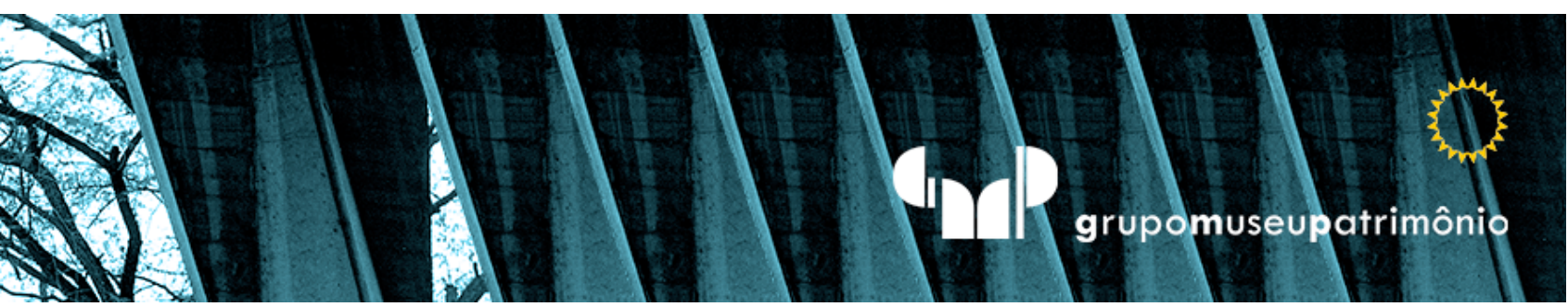

\title{
Tantas Marias
}

\author{
Tantas Marías
}

\section{So many Maries}

Angela Maria Rocha

Professora Livre Docente, FAU USP, São Paulo, Brasil amrocha@usp.br 


\title{
Resumo
}

Diversas circunstâncias podem contribuir para o desenvolvimento de obras de arte na música, na literatura ou nas artes visuais e são muitos os exemplos conhecidos. Inegavelmente, o tempo, o local, o vivido (também delírios ou sonhos) provocam interesse e motivação para os artistas e para espectadores. O presente trabalho de pinturas realizadas em série, aqui apresentado, relata uma experiência recorrente, a que muitos artistas recorrem ou recorreram, revisitando obras de arte, estudando-as e nelas se inspirando. Inúmeras vezes nada desse processo se evidencia no resultado. Entretanto, podem expressar inquietação ou curiosidade sobre o fazer da arte e, seguramente, as obras do passado, em qualquer modalidade, são referências para o presente.

Palavras-Chave: Imagem e movimento. Processo criativo. Tempo. Passado. Presente.

\section{Resumen}

Varias circunstancias pueden contribuir al desarrollo de obras de arte en la música, la literatura o las artes visuales y hay muchos ejemplos conocidos. Sin lugar a dudas, el tiempo, el lugar, lo vivido (también delirios o sueños) provocan interés y motivación en los artistas y en los espectadores. El presente trabajo de pinturas realizadas en serie, aquí presentado, relata una experiencia recurrente, a la que muchos artistas recurren o han recurrido, revisitando obras de arte, estudiándolas e inspirándose en ellas. Innumerables veces, nada de este proceso es evidente en el resultado. Sin embargo, pueden expresar inquietud o curiosidad por la realización del arte y, seguramente, obras del pasado, en cualquier modalidad, son referentes del presente.

Palavras-Clave: Imagen y movimiento. Proceso creativo. Tiempo. Pasado. Presente.

\begin{abstract}
Various circumstances can contribute to the development of works of art in music, literature or the visual arts and there are many known examples. Undeniably, the time, the place, the experience (also delusions or dreams) provoke interest and motivation for artists and spectators. The present work of paintings carried out in series, presented here, reports a recurrent experience, which many artists resort or have resorted to, revisiting works of art, studying them and drawing inspiration from them. Countless times, none of this process is evident in the result. However, they can express disquiet or curiosity about the making of art and, surely, works from the past, in any modality, are references for the present.
\end{abstract}

Keywords: Image and movement. Creative process. Time. Past. Present. 


\section{INTRODUÇÃO}

É preciso dizer, desde já, que o mundo profano na sua totalidade,
o Cosmo totalmente dessacralizado, é uma descoberta recente na história do espírito humano.

(ELIADE, Mircea,1996, p.19)

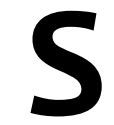

ob a epígrafe de Mircea Eliade, pretendeu-se trazer aqui, para o presente, uma série de pinturas desenvolvidas a partir do encontro com uma antiga pintura (1262-1279) de caráter religioso referente à Anunciação. Na situação presente em que temos vivido com a pandemia, o tempo se expande frente a imagens encontradas no computador ou no celular e, para quem tem por hábito e interesse nas práticas das artes visuais, investigar e pesquisar pinturas e artistas; com frequência é possível se manter em imagens, descobrindo-as inesperadamente com outros olhares. Foi o que aconteceu com a pintura que pode ser encontrada no Google ainda hoje ${ }^{1}$, a qual presidiu o desenvolvimento desta série dos seis trabalhos aqui apresentados também em pintura, ao vê-la como ponto de partida e deslocada

\footnotetext{
${ }^{1}$ Consultar https://artmuseum.princeton.edu/es/collections/maker/5010
} 
no tempo e no espaço, não só do presente, mas também no próprio contexto das imagens de pinturas apresentadas no Google referentes ao mesmo tema. Não é preciso esforço na procura da identificação da época e lugar de origem, que acompanha a imagem. Ela própria captura o interesse e a curiosidade, tornando-a especial logo à primeira vista em relação às demais. Trata-se de Maria e o anjo, como que surpreendidos em movimento, destacando-se à frente de um fundo estático, como um cenário teatral bizantino. Realizada em Siena, na Itália, sobre madeira, é pequena e atualmente sob os cuidados de universidade de Princepton. É parte de um conjunto de pinturas que foi desmembrado.

\section{ANUNCIAÇÃO EM 1262-1279}

O contraste entre o fundo, com as figuras em movimento, é que parece capturar de imediato a atenção. Ao mesmo tempo esse fundo, referenciado na tradicional pintura bizantina, também conhecida como perspectiva inversa (Floriênski, 2012) atrás das duas figuras, se apresentando tão próximas e, ao mesmo tempo, indicando através de suas dimensões, desproporcionalmente reduzidas, que são como um cenário; a indicação de um contexto onde se desenvolve a cena. Tudo isso são referências que conferem o tempo histórico e o lugar em que foi realizada essa pintura de Guido da Siena.

A imagem teatral em ação cenográfica, confirma-se como cenário quando se encontra outra pintura do mesmo artista que faz uso de recurso similar como fundo em uma cena dramática do Flagelo de Cristo. Nos dois casos, aparentemente se sugere um espaço aberto e nas proximidades, ou no contexto, de um espaço urbano contemporâneo dos personagens presentes na pintura. No modo de representação do espaço vigente na época, anterior ao emprego da perspectiva linear que só passou a predominar posteriormente na pintura, representou interesse relativo, tornando-se contexto ou cenário de fundo. Assim, pode-se dizer que se assemelha, numa percepção atual, a uma composição abstrata e estática, contribuindo para a atenção do espectador o centrar-se nas figuras em movimento em primeiro plano, capturando um olhar que se dirige ora para o anjo, ora para a atemorizada Maria: para o movimento de seus corpos, pelos olhares que se cruzam à distância 
prescrutando as intenções. Em movimento acelerado e leve o anjo avança com o braço estendido para Maria que receia, ou tem intenção de recuo em um movimento que a paralisa. Do alto, um facho de luz foca os personagens.

\section{TEMPO PASSA...}

Hoje tornou-se possível identificar a cena como um fotograma em que se pode ver a suspenção do instante de um movimento. Um momento que ainda não é a Anunciação, mas sim a sua eminência: o prenúncio que atesta a inevitabilidade do sagrado encontro de duas figuras cumprindo a prescrição anunciada no passado.

Com os olhares profanos dos tempos atuais, mesmo com a atenção distraída como define Gianni Vattimo (1996), ainda que rápida e de passagem no Google, a presença do tempo nesta pintura, se identifica na corrente temporal da história da arte. Deterse nela: procurar visualizar o que essa fração de movimento como um fotograma poderia revelar, se abstraída do sentido sagrado implicado e, mobilizando o imaginário para as situações cotidianas e praticamente invisíveis não presentes aqui, mas em outros fotogramas. Eventos circunstanciais decorrentes do embate entre personagens estabelecidos na figuração da pintura, poderiam ser projetados.

Seria de se perguntar: como se situaria uma jovem andando sozinha à noite na rua por uma cidade como São Paulo, e se em um momento em que um veículo policial faz ronda noturna e, com uma potente lanterna, do alto de um viaduto a iluminasse. E se um anjo fosse uma fantasia dela, ou um grafite numa parede. Ou quem sabe a sua crente expectativa de um acompanhante. E se ela sentisse medo da própria sombra. Ou seria mais protegida se acompanhada e por Nossa Senhora? Será que as mulheres no oriente médio começaram a usar burka para se sentirem protegidas. $E$ se fosse uma prostituta à espera de uma saída.

Trata-se aqui de ressignificações em série ou é uma experimentação em atribuir ainda agora algum sentido a essa pintura que, apesar do caráter emblemático da imagem a que se refere, é objeto de alguma atenção distraída, como qualquer outra em todos os tempos. Ou então é a imagem que suspende o acontecimento 
que Ihe daria sentido e convoca a experiência de desdobrar algum sentido que possa suprir o que falta.

Como declara Agamben, no prefácio da edição francesa do livro Infância e História: "Toda obra escrita pode ser considerada como prólogo de uma obra jamais escrita..." (AGAMBEN, 2005, p.9), assim também o presente texto, referente à experiência na realização da série Tantas Marias, seria o prólogo de alguma escrita que também nunca venha a se realizar. A pintura de Guido da Siena sugeriu a ideia de que ela poderia ter sido a primeira de uma série que jamais foi realizada por ele. Como se fosse um fotograma à espera dos demais...

Na pintura, é o que sempre acontece: visitar obras que precedem, através da história da arte, através das realizadas hoje, é obrigatório para que um artista possa olhar com outros olhos, também a realidade presente, sabendo que toda imagem revela o tempo e se fixa no tempo. Até mesmo fotogramas que ficaram perdidos ou desprezados nas montagens. Assim acontecem as pinturas em séries.

Quem já teve a oportunidade de assistir os vídeos de Bill Viola que podem ser encontrados no YouTube, há de concordar sobre o pertencimento da imagem ao tempo, como indica AGAMBEN( 2012, p.21) ao citar o próprio Viola sobre isso, em entrevista impressa em catálogo de uma de suas exposições:

\section{A essência da mídia visual é o tempo [...] as imagens vivem dentro de nós [...] nós somos databases viventes de imagens - colecionadores de imagens - e já que as imagens estão dentro de nós, elas não cessam de se transformar e crescer[...]}

Não é em vão que, rever obras do passado evoque questões que, no presente, desdobram-se em séries quando, em resposta ao nosso cotidiano vivido nos indagamos: e se ...? 



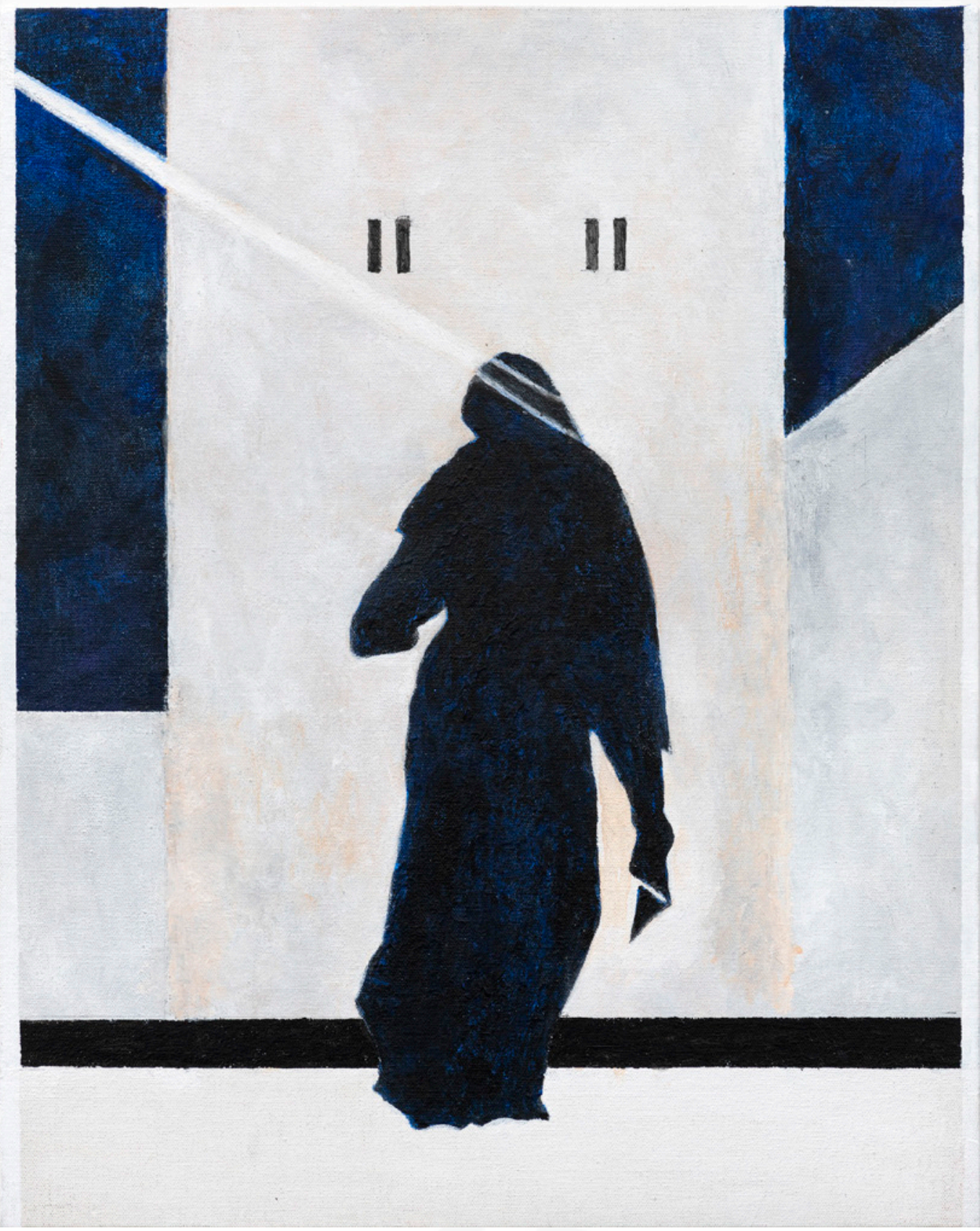

Angela Rocha,"Maria 2", 2020. Acrílica sobre painel entelado,24×30cm. Foto: Sérgio Guerini. 


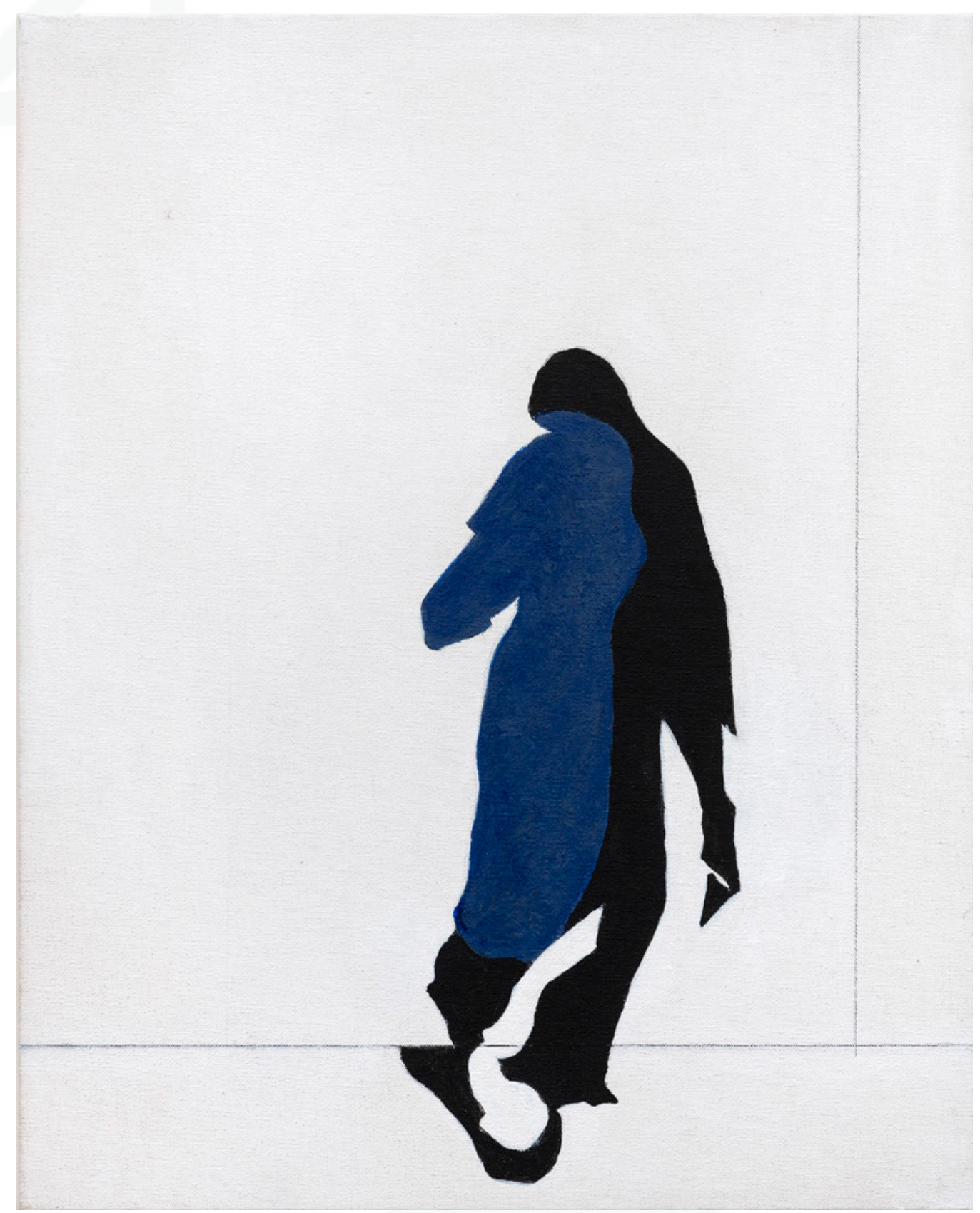

Angela Rocha, "Maria 3", 2020. Acrílica sobre painel entelado,24×30cm.

Foto: Sérgio Guerini. 


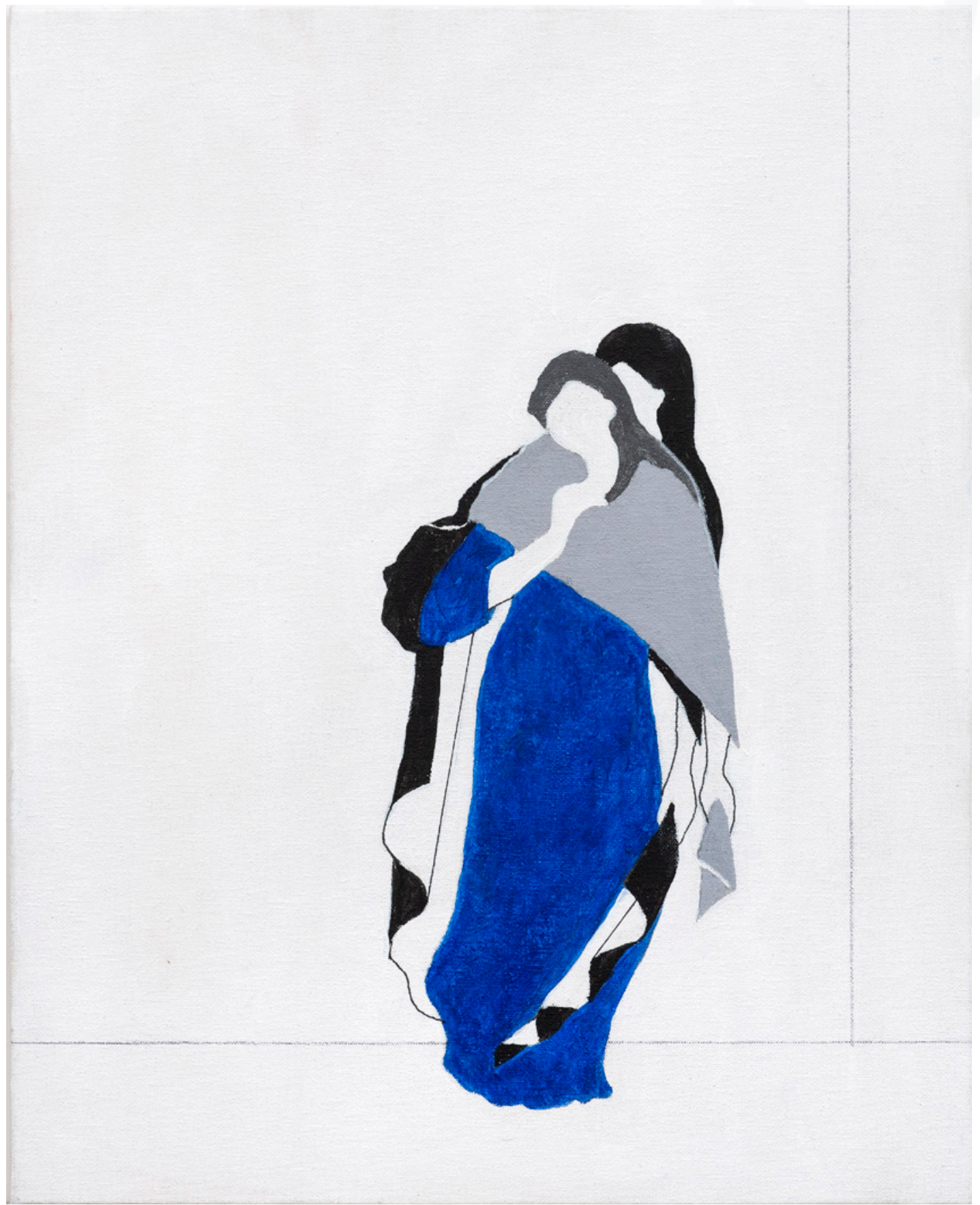

Angela Rocha,"Maria 4", 2020. Acrílica sobre painel entelado, $24 \times 30 \mathrm{~cm}$. Foto: Sérgio Guerini. 


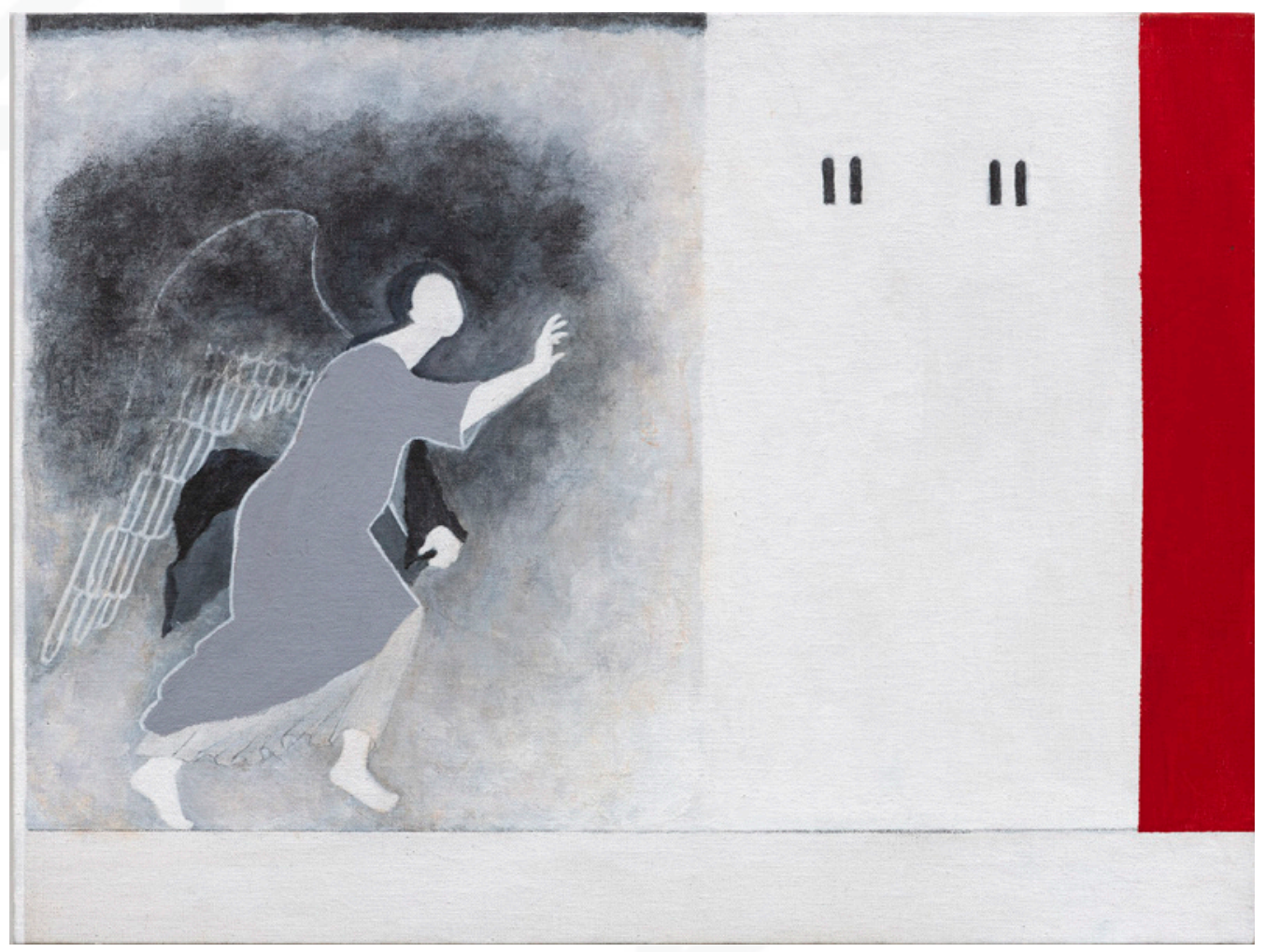

Angela Rocha,"Maria 5", 2020. Acrílica sobre painel entelado, 40×30cm. Foto: Sérgio Guerini. 


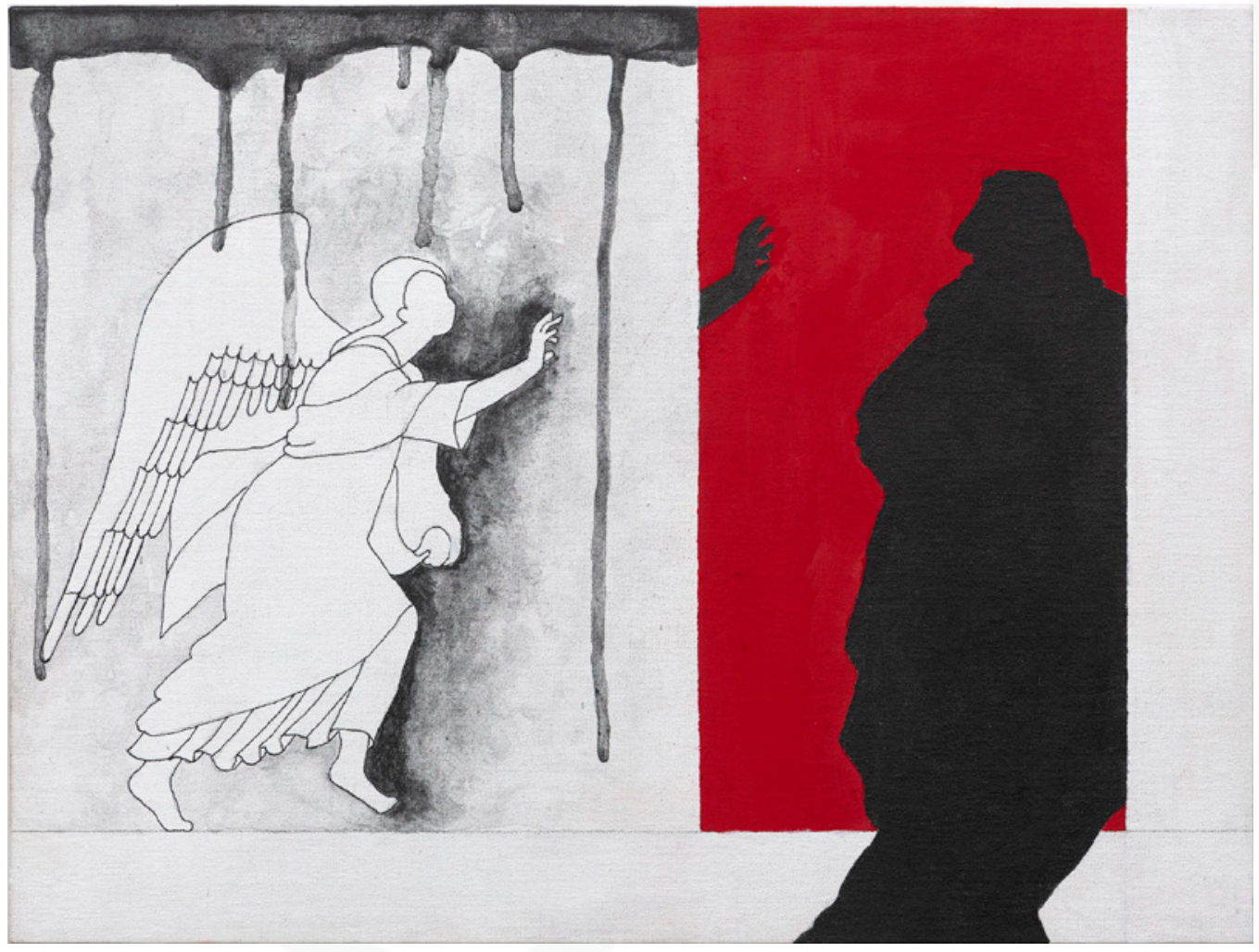

Angela Rocha,"Maria 6", 2020. Acrílica sobre painel entelado, 40x30cm. Foto: Sérgio Guerini.

\section{BIBLIOGRAFIA CITADA}

https://artmuseum.princeton.edu/es/collections/maker/5010

AGAMBEN, Giorgio. Ninfas. São Paulo: Hidra, 2012.

AGAMBEM, Giorgio. Infância e História. Belo Horizonte: Ed. UFMG, 2005.

FLORIÊNSKI, Pável. A perspectiva inversa. São Paulo: Editora 34, 2012

VATTIMO, Gianni. O fim da modernidade. São Paulo: Ed. Martins Fontes, 1996. 